\title{
Neonatal Pattern of Breathing during Active and Quiet Sleep after Maternal Administration of Meperidine ${ }^{1}$
}

\author{
JAMIL HAMZA. ${ }^{2}$ MALIK BENLABED, EDITH ORHANT, PIERRE ESCOURROU, LILIA CURZI- \\ DASCALOVA, AND CLAUDE GAULTIER \\ Laboratory of Physiology. Department of Anesthesiology, and INSERM CJF 8909, Hôpital Antoine Béclère, \\ Clamart, France
}

\begin{abstract}
The aim of this study was to reappraise the effects of maternal meperidine administration on breathing pattern during the first hours of life taking into account the state of alertness. Because breathing instability is more pronounced during active sleep, we hypothesized that meperidine administration might create a greater risk for respiratory instability during active sleep, the prominent sleep state in newborns. We studied eight full-term, healthy newborns whose mothers had received a continuous i.v. infusion of meperidine $(81 \pm 9 \mathrm{mg})$ that was terminated $5.5 \pm 2.1 \mathrm{~h}$ before delivery. These infants were compared with a control group of eight full-term newborns whose mothers did not receive any opioids. In both groups, all babies were delivered vaginally after a normal labor and had Apgar scores of 9 or 10 at 1 and 5 min. Neonatal gastric secretion and maternal venous and umbilical venous blood were sampled at delivery for determination of meperidine concentration. From 60 to 300 min after delivery, behavioral sleep states and thoracic and abdominal movement as well as transcutaneous arterial oxygen saturation $\left(\mathrm{SaO}_{2}\right)$ were monitored continuously. The number of apneic spells lasting more than $3 \mathrm{~s}$ during $100 \mathrm{~min}$ of recording and the percentage of time with $\mathrm{SaO}_{2}$ below $90 \%$ in each sleep state were recorded. During quiet sleep, all respiratory variables were similar in both groups. During active sleep, there were significantly more apneic episodes (37.1 \pm 25.1 versus $11.2 \pm 13.9)$ and a higher percentage of time with $\mathrm{SaO}_{2}<90 \%(14.3 \pm 16.7 \%$ versus $1.3 \pm 1.5 \%)$ in the meperidine group than in the control group $(p<0.01)$. In addition, the percentage of time with $\mathrm{SaO}_{2}<90 \%$ was significantly correlated with maternal meperidine dose ( $p$ $<0.02)$, drug-delivery interval $(p<0.01)$, and gastric concentration of meperidine $(p<0.01)$. These data show that maternal administration of meperidine induces respiratory abnormalities in healthy, full-term newborns that occur only during active sleep. This result indicates that the state of alertness has to be characterized during the monitoring of long-term neonatal respiratory effects of any narcotic agent. In addition, we speculate that maternal meperidine administration may provoke more severe respiratory disturbances in at-risk neonates and that respiratory monitoring during the first hours of life may be useful in these newborns. (Pediatr Res 32: 412-416, 1992)
\end{abstract}

Received December 12, 1991; accepted May 21, 1992.

Correspondence and reprint requests: $\mathrm{Pr}$. Gaultier, Laboratory of Physiology, Hópital Antoine Béclère, 157 rue de la Porte de Trivaux, 92141 Clamart Cédex, France.

Presented in part at the meeting of the American Society of Anesthesiologists. New Orleans, LA, October 1989.

2 Present address: Department of Anesthesiology, Hòpital St. Vincent de Paul, 75014 Paris, France.

\author{
Abbreviations \\ QS, quiet sleep \\ AS, active sleep \\ CRS, compliance of total respiratory system \\ $\dot{V} E$, minute ventilation \\ VT, tidal volume \\ $\mathrm{SaO}_{2}$, arterial oxygen saturation \\ $\mathbf{R R}$, respiratory rate
}

Despite the well-known placental transfer of meperidine (1) and the long neonatal half-life of both meperidine (2) and its active metabolite normeperidine (3), it is the drug most widely used to control labor pain. The risks of neonatal depression (4) at birth (low Apgar score) and long-lasting neurobehavioral impairment $(5,6)$ have been recognized for a long time. Previous studies have documented neonatal respiratory effects of meperidine during the lst hour of life: decreased $\mathrm{SaO}_{2}$ (7), lower $\dot{\mathrm{VE}}(8)$, increased arterial $\mathrm{PCO}_{2}(9)$, and less ventilatory response to $\mathrm{CO}_{2}$ (10) have been demonstrated.

However, none of these previous studies has documented noninvasive measurement of neonatal breathing for several hours after birth or attempted to assess the state of alertness during measurements. It is relevant to assess neonatal breathing pattern in relation to sleep states inasmuch as instability in the breathing pattern is more pronounced in AS than in QS. Finally, recent respiratory investigations during sleep in newborns or in infants have shown that stress, such as hyperthermia (11) or sleep deprivation (12), constitutes a risk for unstable breathing patterns during AS. We may speculate that meperidine administration is a greater risk factor for respiratory instability in AS.

For these reasons, we reappraised the neonatal respiratory effects of maternal meperidine administration on neonatal respiration. We evaluated in full-term neonates, with or without maternal administration of meperidine, the neonatal pattern of breathing and states of alertness for several hours after birth using noninvasive respiratory measurements. In addition, we measured CRS to confirm previous data showing a lack of effect of maternal meperidine administration on lung mechanics (10). Finally, we determined the relationship between these respiratory measurements and concomitant pharmacologic measurements.

\section{PATIENTS AND METHODS}

Patients. After informed parental consent and Ethics Committee approval, 16 term neonates were involved in the study. Only healthy neonates with normal Apgar scores, i.e. $>8$ at 1 and $5 \mathrm{~min}$, delivered vaginally after a normal course of labor were included. The babies were born of healthy mothers who 
had uncomplicated pregnancies and no history of drug abuse or tobacco smoking. The study group consisted of eight term newborns whose mothers received meperidine. The demographic variables of the study group were as follows: gestational age, 40 $\pm 0.7 \mathrm{wk}$; birth weight, $3472 \pm 296 \mathrm{~g}$; height, $50 \pm 2.1 \mathrm{~cm}$; Apgar score, $9.9 \pm 0.3$ at $1 \mathrm{~min}$ and 10 at $5 \mathrm{~min}$; and duration of labor, $6 \pm 1.5 \mathrm{~h}$. A continuous i.v. infusion of meperidine was administered by the midwife for irregular uterine contractions during the latent phase of labor (cervical dilation $<2 \mathrm{~cm}$ ) as follows: 25 $\mathrm{mg}$ as an i.v. bolus followed by a continuous i.v. infusion of 25 $\mathrm{mg} / \mathrm{h}$. The total dose never exceeded $125 \mathrm{mg}$ and the duration of the infusion never exceeded $4 \mathrm{~h}$. Meperidine infusion was stopped by the midwife as soon as the parturient was in active labor (cervical dilation $=2 \mathrm{~cm}$ and regular uterine contractions) and admitted to the delivery room. The time after the discontinuation of meperidine until delivery (the drug-delivery interval) was in all cases longer than $3 \mathrm{~h}$ (mean $\pm \mathrm{SD}, 5.5 \pm 2.1 \mathrm{~h}$ ). The control group consisted of eight term newborns whose mothers did not receive meperidine before the active phase of labor.The clinical variables of the control group were as follows: gestational age, $40 \pm 0.8$ wk; birth weight, $3413 \pm 477 \mathrm{~g}$; height, $49.8 \pm 1.9$ $\mathrm{cm}$; Apgar score, $9.7 \pm 0.5$ at $1 \mathrm{~min}$ and 10 at $5 \mathrm{~min}$; and duration of labor, $6.7 \pm 2.7 \mathrm{~h}$. During the active phase of labor, when cervical dilation was 3-4 cm, epidural analgesia (bupivacaine $0.25 \%$ ) was used for maternal pain relief in both groups. Maternal bupivacaine dose was similar in both groups, i.e. 0.99 \pm 0.2 and $0.99 \pm 0.26 \mathrm{mg} / \mathrm{kg}$ in the study and control group, respectively. No narcotic drugs (other than meperidine in the study group) were used in either group.

Pharmacologic study. In the study group, maternal meperidine dose $(\mathrm{mg} / \mathrm{kg})$ and drug-delivery interval $(\mathrm{h})$ calculated from the end of the i.v. infusion to delivery were noted for each newborn at birth. Neonatal gastric secretion $(10 \mathrm{~mL})$ and maternal venous $(10 \mathrm{~mL})$ and umbilical venous blood $(10 \mathrm{~mL})$ were sampled at delivery, separated, and kept frozen at $-20^{\circ} \mathrm{C}$. Subsequently, meperidine concentration was determined by gas chromatography (13). The variability of this determination is less than $12 \%$ for a meperidine concentration of $30 \mathrm{ng} / \mathrm{mL}$.

In addition to maternal meperidine dose, drug-delivery interval, and maternal venous and umbilical venous blood meperidine concentration, we measured neonatal gastric concentration of meperidine. The possibility of gastric acid-trapping of meperidine (14) in the fetal stomach may be of importance because subsequent absorption of meperidine by the intestinal tract may increase plasma concentration several hours after birth and may depress respiration at that time.

Respiratory study. The study started $60 \mathrm{~min}$ after delivery and ended $4 \mathrm{~h}$ later. The newborn was placed in an incubator with a temperature of $33^{\circ} \mathrm{C}$ and breathed room air. The mother stayed in the same room throughout the study.

For all neonates studied, the same investigator (J.H.) continuously monitored the state of alertness (awake, QS, and AS) from 60 to $300 \mathrm{~min}$ of life using behavioral criteria (15). Wakefulness was defined by the following criteria: open eyes, ocular movements, and gross body movements, with occasional crying and agitation. AS was defined by the following criteria: closed eyes, rapid ocular movements, rapid movements of lips, fingers, and toes, and irregular respiration. QS was defined by the following criteria: closed eyes, no ocular movements, no body movements (except startles and sighs), and regular respiration. Using behavioral criteria (15), we were unable to characterize periods of indeterminate sleep. However, it has been shown that in fullterm newborns indeterminate sleep occupies only $7 \%$ of the total sleep time (16).

We monitored the pattern of breathing and $\mathrm{SaO}_{2}$ for the entire duration of the study. Measurements using a pneumotachograph connected to a face mask have been shown to increase VT as much as $30 \%$ compared with the VT measured with a noninvasive method that does not stimulate trigeminal afferents (17). Thus, we monitored the pattern of breathing using a noninvasive method, i.e. the inductive plethysmograph (Respitrace 150, Studley Data Systems, UK). $\mathrm{SaO}_{2}$ was monitored using a pulse oximeter (Biox 3700 Ohmeda, Boulder, CO). Thoracic and abdominal movements as well as $\mathrm{SaO}_{2}$ were recorded simultaneously on paper (Gould ES 1000, Ballainvillies, France).

To obtain quantitative measurements of VE and VT, calibration of the Respitrace was performed during the first period of QS observed between 60 and 120 min using a two-compartment model of tidal breathing for $5 \mathrm{~min}$ of quiet breathing (18). During calibration of the Respitrace, newborns breathed room air through a low dead space face mask (Rendell-Baker-Soucek) that allowed an optimal fit to the newborn's face and a pneumotachograph (Fleisch size 0). Instrument dead space was $7 \mathrm{~mL}$. To avoid air leaks and pressure effects on the checks, the mask was fixed with hypoallergenic sterilized strips. Calibration of the Respitrace was not performed during AS because quantitative calibration during AS is still controversial $(18,19)$.

In addition, during the first period of QS between 60 and 120 min, we measured CRS using the multiple occlusion technique (20). Airway occlusion was obtained with a manually activated slide value connected to the Fleish pneumotachograph, which was in turn connected to a differential pressure transducer (Validyne Engineering Corp., Northridge, CA). The airflow signal was integrated to obtain VT. Pressure at the mouth was measured by a differential pressure transducer (Validyne). During each test, a minimum of 10 occlusions were performed at different expired volumes during the first two thirds of the expiratory phase. In the newborn, chest wall compliance is very high, whereas lung compliance is low; therefore, CRS is a reliable assessment of lung compliance (21). CRS was not measured during AS because the reliability of the technique depends upon a stable end-expiratory volume of the respiratory cycles preceding occlusion. This is difficult to obtain during AS because of the irregularity of the breathing pattern.

From 120 to $300 \mathrm{~min}$, the assessment of behavioral states and noninvasive respiratory monitoring (Respitrace and $\mathrm{SaO}_{2}$ ) were continuously recorded with special caution to avoid any neonatal disturbance (no noise, no bright light, minimal handling of the neonate).

Data analysis. One independent investigator, blinded to the neonate's group assignment, performed analysis of the recordings.

For recordings made from 60 to $120 \mathrm{~min}$, the coefficients of correlation between VT measured by pneumotachography and Respitrace during QS were $>0.85$ in all newborns.

CRS was calculated as the slope of the linear relationship between total respiratory system relaxation pressure measured at the mouth and the lung volume at the occlusion. The mean correlation coefficient between pressures and volumes at occlusion ranged between 0.85 and 0.98 .

For recordings made from 120 to $300 \mathrm{~min}$, the time spent in each state of alertness was calculated, and visual analysis of the Respitrace and pulse oximeter signals in each state was performed after deletion of periods of artefacts due to gross body movements (mainly during wakefulness). The following variables were tabulated: 1) During QS, RR, VT, and VE were calculated in each period of QS by averaging 30 respiratory cycles; and 2) during both QS and AS, the number of central apneas per $100 \mathrm{~min}$ of tracing (defined as absence of respiratory movements for more than $3 \mathrm{~s}$ ) and the percentage of time spent with a $\mathrm{SaO}_{2}<90 \%$ in each sleep state were calculated.

All results are expressed as mean $\pm \mathrm{SD}$. To compare respiratory variables measured during $Q S$ between the two groups of neonates, we used the nonparametric test of Mann-Whitney. To compare respiratory variables measured in both sleep states within each group and between groups, we used two-way analysis of variance followed by Fisher's exact test. For statistical analysis, the level of significance was taken to be $p<0.05$.

After eight subjects had been studied in each group, there was 
a statistically significant difference between groups; therefore, we did not study additional newborns.

To examine the correlation between pharmacologic and respiratory data in the meperidine group, we used the Spearman's rank correlation test. For statistical analysis, the level of significance was taken to be $p<0.05$.

\section{RESULTS}

State of alertness. There was no difference in the duration of interpretable monitoring between the groups (172.5 \pm 15.8 versus $168 \pm 15.1 \mathrm{~min})$. The time spent in each state did not differ significantly between the groups: time spent in wakefulness was $21.1 \pm 12.1$ versus $13.2 \pm 5.4 \%$, in AS $55.8 \pm 7.7$ versus $53.5 \pm$ $3.2 \%$, and in QS $23.1 \pm 11.4$ versus $33.1 \pm 5.1 \%$ for study and control groups, respectively.

Respiratory data during quiet sleep. CRS, VE, mean inspiratory flow (VT/inspiratory time), and duty cycle (inspiratory time/total duration of the respiratory cycle) were not significantly different between groups (Table 1). However, VT was significantly higher and RR tended to be lower in the study group (Table 1).

The number of apneic spells per $100 \mathrm{~min}$ was similar in both groups $(4.4 \pm 11$ in study group versus $2.3 \pm 2.7$ in control group) as well as the percentage of time spent with $\mathrm{SaO}_{2}<90 \%$ $(0.3 \pm 0.6 \%$ in study group versus $0 \%$ in control group) (Table 2, Fig. 1). The mean duration of apneas was $4 \pm 1.7$ versus 3.6 $\pm 0.9 \mathrm{~s}$ for study and control groups, respectively (NS).

Respiratory data during active sleep. The number of apneas per 100 min was significantly higher in the study group (37.1 \pm $25.1)$ than in the control group $(11.2 \pm 13.9)(p<0.01)$ (Table 2). The mean duration of apneas was longer in the study group $(5.3 \pm 0.9 \mathrm{~s})$ than in the control group $(3.8 \pm 0.6 \mathrm{~s})(p<0.05)$. The mean duration of the longest apnea was longer in the study group $(10.4 \pm 2.2 \mathrm{~s})$ than in the control group $(5.4 \pm 2.1 \mathrm{~s})(p<$ 0.01 ). The incidence of apneas $\geq 10 \mathrm{~s}$ in each subject in both groups is indicated in Table 2. The difference in incidence in both groups, was statistically significant $(p<0.01)$. The time spent in apnea expressed as a percentage of AS time was significantly longer in the study group $(3.13 \pm 2.0 \%)$ than in the control group $(0.80 \pm 1.1 \%)(p<0.01)$. The percentage of time with heart rate below 100 beats/min was significantly higher in the study group $(16 \pm 4.6 \%)$ than in the control group $(4 \pm 3.5 \%)$ $(p<0.01)$.

The percentage of time spent with $\mathrm{SaO}_{2}<90 \%$ was significantly higher in the study group $(14.3 \pm 16.7 \%)$ than in the control group $(1.3 \pm 1.5 \%)$ (Table 2, Fig. 1). The minimal value for $\mathrm{SaO}_{2}$ in each subject of both groups during AS is indicated in Table 2. The mean minimal $\mathrm{SaO}_{2}$ is significantly lower in the meperidine group $(p<0.01)$.

Pharmacologic measurements. The individual pharmacologic parameters of the eight newborns in the study group are shown in Table 3. Umbilical venous blood concentration of meperidine was not correlated with the total meperidine dose given to the mother or with the drug-delivery interval. In contrast, gastric concentration of meperidine was significantly correlated with

Table 1. Respiratory parameters measured during $Q S$ (mean $\pm S D)$

\begin{tabular}{lcc}
\hline & Meperidine & Control \\
\hline $\mathrm{CRS}\left(\mathrm{mL} / \mathrm{cm} \mathrm{H} \mathrm{H}_{2} \mathrm{O} / \mathrm{kg}\right)$ & $0.71 \pm 0.11$ & $0.70 \pm 0.09$ \\
$\mathrm{VT}(\mathrm{mL} / \mathrm{kg})$ & $4.8 \pm 0.6^{*}$ & $4.1 \pm 1.1$ \\
$\mathrm{RR}(\mathrm{breath} / \mathrm{min})$ & $46.3 \pm 6.8$ & $57.9 \pm 17$ \\
$\dot{\mathrm{VE}}(\mathrm{mL} / \mathrm{kg} / \mathrm{min})$ & $222 \pm 45$ & $223 \pm 59$ \\
$\mathrm{Ti} / \mathrm{Ttot} \dagger$ & $0.39 \pm 0.02$ & $0.39 \pm 0.03$ \\
$\mathrm{VT} / \mathrm{Ti}(\mathrm{mL} / \mathrm{s}) \ddagger$ & $33.1 \pm 7$ & $32.3 \pm 8.6$ \\
\hline
\end{tabular}

$* p<0.01$ vs control.

$\dagger \mathrm{Ti} / \mathrm{Ttot}$, inspiratory time/total duration of respiratory cycle.

$\ddagger$ VT/Ti, VT/inspiratory time. both total meperidine dose given to the mother $(r=0.94 ; p<$ $0.01)$ and with drug-delivery interval $(r=0.89 ; p<0.01)$.

Correlations between respiratory and pharmacologic measurements. During QS, no correlation between any respiratory measurement (CRS, RR, VT, VE, number of apneas, or percentage of time with $\mathrm{SaO}_{2}<90 \%$ ) and pharmacologic measurements was found.

During AS, there was no correlation between the number of apneas per $100 \mathrm{~min}$ and all the pharmacologic measurements. In contrast, there was a significant correlation between the percentage of time spent with $\mathrm{SaO}_{2}<90 \%$ during $\mathrm{AS}$ and the total meperidine dose given to the mother $(r=0.83 ; p<0.01)$, drugdelivery interval $(r=0.87 ; p<0.01)$, and gastric concentration of meperidine $(r=0.88 ; p<0.01)$.

\section{DISCUSSION}

The major finding of this study is that AS is a period at risk for respiratory instability in newborns whose mothers received meperidine. Compared with the control group, newborns of the meperidine group were more often apneic and spent more time with a low $\mathrm{SaO}_{2}$ during AS but not during QS. Furthermore, the time spent with low $\mathrm{SaO}_{2}$ during $\mathrm{AS}$ was significantly related to the total meperidine dose given to the mother and to the neonatal gastric concentration of meperidine.

Meperidine maternal administration did not affect the newborn's sleep organization. There was no significant difference between time spent in QS and wakefulness. To the best of our knowledge, no previous study has reported sleep organization data in newborns exposed to maternal meperidine.

We speculate that maternal meperidine administration may cause a greater risk for respiratory instability in AS than in QS because: 1 ) in newborns, instability in the breathing pattern is more pronounced in AS than in QS (22), and 2) stress, such as hyperthermia (11) or sleep deprivation (12), has been shown to induce more unstable breathing patterns during AS than in QS.

In addition to the enhancement of breathing pattern instability during AS, maternal meperidine administration induced impairment in oxygenation. In the control group, time spent with $\mathrm{SaO}_{2}$ $<90 \%$ during AS was close to the time spent in apnea. In contrast, in the meperidine group, the time spent with $\mathrm{SaO}_{2}<$ $90 \%$ during AS was more than four times greater than the time spent in apnea. This difference may indicate that the meperidine group had, in addition to longer apnea time, periods of hypoventilation during AS. Because quantitative calibration of the inductance plethysmograph is still controversial during AS (18, 19), we did not quantify the decrease in ventilation.

Meperidine-induced depression of ventilatory response to chemical stimuli has been demonstrated previously. In awake adults, ventilatory responses to hypercapnia and hypoxia were depressed for up to $90 \mathrm{~min}$ after i.v. meperidine administration (23). In newborns with normal Apgar scores exposed to 1-1.5 $\mathrm{mg} / \mathrm{kg}$ of maternal meperidine, Gerhardt et al. (10) reported a depression of the ventilatory response to $\mathrm{CO}_{2}$ during the 1 st hour of life in two thirds of the newborns studied. Furthermore, as in adults during rapid eye movement sleep compared to non-rapid eye movement sleep $(24,25)$, the neonatal ventilatory responses to chemical stimuli are known to be decreased during AS when compared with QS $(26,27)$. We suggest that maternal meperidine administration enhances the instability of breathing inherent to AS and potentiates the decreased response to chemical stimuli during AS accounting for the high percentage of time with suboptimal $\mathrm{SaO}_{2}$ observed during $\mathrm{AS}$ in meperidine-exposed newborns.

Time spent with $\mathrm{SaO}_{2}<90 \%$ during AS was significantly related to maternal dose and drug-delivery interval, confirming previous studies correlating either low Apgar scores with increased drug-delivery interval (4) or neurobehavioral scores with maternal dose (28). The correlation of time spent with $\mathrm{SaO}_{2}<$ $90 \%$ with neonatal gastric concentration of meperidine is a new 
Table 2. Number of apneas and time spent with $\mathrm{SaO}_{2}<90 \%$ during $Q S$ and $A S$ in study and control groups

\begin{tabular}{|c|c|c|c|c|c|c|}
\hline & \multicolumn{3}{|c|}{ No. of apneas } & \multirow{2}{*}{\multicolumn{2}{|c|}{$\begin{array}{c}\% \text { Time spent with } \mathrm{SaO}_{2} \\
<90 \%\end{array}$}} & \multirow{3}{*}{$\begin{array}{c}\text { Lowest } \mathrm{SaO}_{2} \\
\text { in } \mathrm{AS}(\%)\end{array}$} \\
\hline & \multicolumn{2}{|c|}{$>3 \mathrm{~s} / 100 \mathrm{~min}$} & \multirow[b]{2}{*}{$>10 \mathrm{~s}$ in $\mathrm{AS}$} & & & \\
\hline & QS & AS & & QS & AS & \\
\hline \multicolumn{7}{|l|}{ Study group } \\
\hline 1 & 1.75 & 14.7 & 0 & 0 & 0 & 92 \\
\hline 2 & 31.6 & 80.8 & 1 & 0 & 5.1 & 82 \\
\hline 3 & 1.45 & 60.7 & 3 & 0 & 5.7 & 84 \\
\hline 4 & 0 & 47.4 & 5 & 0 & 12.7 & 70 \\
\hline 5 & 0 & 29.9 & 0 & 0 & 13.3 & 76 \\
\hline 6 & 0 & 4.2 & 1 & 1.6 & 8.1 & 85 \\
\hline 7 & 0 & 22.9 & 1 & 0 & 53.7 & 78 \\
\hline 8 & 0 & 35.9 & 2 & 0.6 & 15.8 & 82 \\
\hline Mean \pm SD & $4.35 \pm 11$ & $37.1 \pm 25.1^{*}$ & $2.25 \pm 2.10^{*}$ & $0.3 \pm 0.6$ & $14.3 \pm 16.7^{*}$ & $81.1 \pm 6.1^{*}$ \\
\hline \multicolumn{7}{|l|}{ Control group } \\
\hline 1 & 3.4 & 2.4 & 0 & 0 & 0.3 & 89 \\
\hline 2 & 2.3 & 8.9 & 0 & 0 & 4.2 & 88 \\
\hline 3 & 0 & 4 & 0 & 0 & 0.2 & 89 \\
\hline 4 & 0 & 4.9 & 0 & 0 & 0.9 & 87 \\
\hline 5 & 1.6 & 7 & 0 & 0 & 0 & 93 \\
\hline 6 & 8 & 45 & 2 & 0 & 0 & 92 \\
\hline 7 & 3.3 & 9.8 & 0 & 0 & 2.5 & 88 \\
\hline 8 & 0 & 7.6 & 0 & 0 & 2 & 89 \\
\hline Mean \pm SD & $2.32 \pm 2.7$ & $11.2 \pm 13.9$ & $0.25 \pm 0.66$ & 0 & $1.3 \pm 1.5$ & $89.4 \pm 1.9$ \\
\hline
\end{tabular}

$* p<0.01$ vs control group.

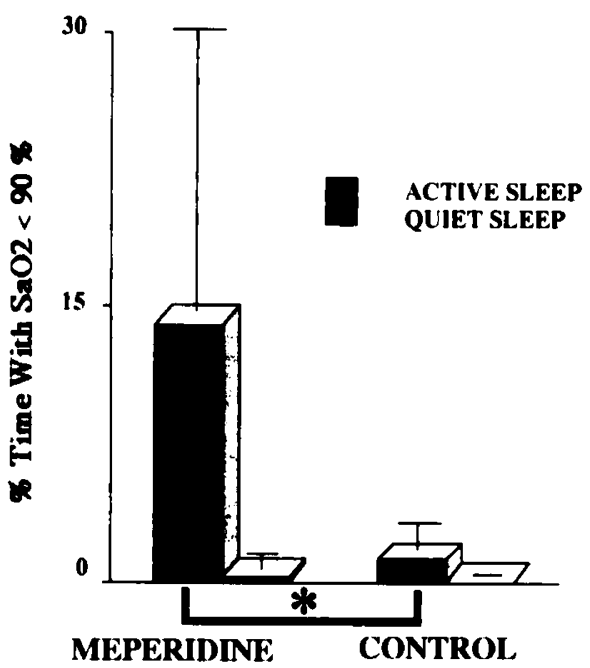

Fig. 1. Percentage of time with $\mathrm{SaO}_{2}<90 \%$ during sleep states. ${ }^{*}, p$ $<0.01$ vs control group. finding. Because fetal gastric fluid is a mixture of amniotic fluid swallowed by the fetus and fetal gastric secretion, the gastric fluid concentration of meperidine might reflect meperidine uptake either from maternal plasma by amniotic fluid or from fetal circulation or both. It has been shown that amniotic fluid transfer of meperidine from maternal plasma occurs during pregnancy (29). Furthermore, the ratio of the concentration of meperidine in amniotic fluid to that in maternal plasma increases with the time elapsed from maternal meperidine administration (29), leading to its accumulation in the amniotic fluid. This could be explained by the ionization of meperidine in amniotic fluid, because meperidine is a weakly basic drug and the $\mathrm{pH}$ of amniotic fluid is lower than that of maternal plasma (30). Thus, the nonionized fraction of meperidine available for diffusion back to the maternal plasma is reduced. Moreover, unbound meperidine in amniotic fluid may well be higher than in maternal plasma, because protein binding of other weakly basic narcotics has been shown to be very low in the amniotic fluid (31). Therefore, during labor, the fetus might swallow amniotic fluid containing a significant amount of unbound, partially ionized meperidine. Because fetal gastric $\mathrm{pH}$ is lower than that of the amniotic fluid (32), ingested meperidine may be further ionized. This ionized fraction is not easily transferred back to the fetal circulation and thus is not cleared from the fetus at the placental

Table 3. Pharmacologic variables*

\begin{tabular}{cccccc}
\hline $\begin{array}{c}\text { Neonates } \\
\text { (group M) }\end{array}$ & $\begin{array}{c}\text { Maternal } \\
\text { dose }(\mathrm{mg} / \mathrm{kg})\end{array}$ & DDI $(\mathrm{h})$ & UVM $(\mu \mathrm{g} / \mathrm{mL})$ & UVM/MVM & GM $(\mu \mathrm{g} / \mathrm{mL})$ \\
\hline 1 & 1.08 & 5.4 & 0.07 & 0.5 & 0.27 \\
2 & 0.95 & 3.4 & 0.04 & 0.57 & 0.25 \\
3 & 0.95 & 5.3 & 0.06 & 0.62 & 0.30 \\
4 & 1.04 & 3.5 & 0.05 & 0.78 & 0.22 \\
5 & 1.54 & 5.7 & 0.14 & 0.5 & 0.23 \\
6 & 0.60 & 4.7 & 0.07 & 0.67 & 0.92 \\
7 & 2.0 & 10.3 & 0.06 & 0.70 & 0.56 \\
Mean \pm SD & 1.29 & 5.6 & $0.07 \pm 0.03$ & $0.60 \pm 0.11$ & $0.42 \pm 0.25$ \\
\hline
\end{tabular}

* DDI, drug-delivery interval; UVM, umbilical venous concentration of meperidine; MVM, maternal venous concentration of meperidine: and GM, neonatal gastric concentration of meperidine. 
level. Indeed, gastric trapping of meperidine has previously been documented in adults (33). In addition, a recent study in animals (14) has demonstrated that plasma meperidine concentration is lower and elimination half-life shorter when animals are pretreated with antacids, which decreases the gastric trapping of meperidine. After birth, subsequent absorption of nonionized meperidine from the intestinal tract is enhanced by the higher $\mathrm{pH}$ of the intestinal fluid. This can contribute to prolonged neonatal respiratory effects, as previously suggested in adults with the use of fentanyl (34), another weakly basic narcotic.

During QS, all respiratory data were similar in both the control and the meperidine groups. CRS was not affected by maternal meperidine administration, which is in agreement with a previous study that showed no change in dynamic lung compliance during the 1st hour of life in newborns exposed to a dose of meperidine ranging from 1 to $1.5 \mathrm{mg} / \mathrm{kg}(10)$. However, in this study, states of alertness were not characterized. VE normalized for body weight in the control group was close to VE found in healthy newborns by others using barometric plethysmography $(35,36)$. In our control group, mean inspiratory flow and duty cycle were close to those found in healthy newborns tested using a barometric plethysmograph (37) and were not affected by maternal meperidine administration.

In summary, our reappraisal of respiratory effects of meperidine during the first $5 \mathrm{~h}$ after birth using continuous noninvasive respiratory monitoring and assessment of states of alertness showed that, even in newborns with normal Apgar scores, maternal i.v. administration of meperidine induces significant neonatal respiratory instability. These abnormalities persist for several hours after birth during AS, the prominent sleep state in the newborn. The difference between AS and QS indicates that the state of alertness must be characterized during monitoring of long-term neonatal respiratory effects of meperidine. Moreover, we believe that our data support the clinical usefulness of some simple noninvasive respiratory monitoring techniques, such as pulse oximetry, for several hours after birth in newborns who have been exposed to maternal meperidine.

\section{REFERENCES}

I. Apgar V. Burns JJ, Brodie BB, Papper EM 1952 The transmission of meperidine across the human placenta. Am J Obstet Gynecol 64:1368-1370

2. Caldwell J, Wakile LA, Notarianni L, Smith RL, Correy GJ, Lieberman BA, Beard RW, Finnie MDA. Snedden W 1978 Maternal and neonatal disposition of pethidine in childbirth. A study using quantitative gas chromatography-mass spectrometry. Life Sci 22:589-596

3. Kuhnert BR, Kuhnert PM, Philipson EH, Syracuse CD 1985 Disposition of meperidine and normeperidine following multiple doses during labor II. Fetus and neonate. Am J Obstet Gynecol 151:410-415

4. Shnider SM, Moya F 1964 Effects of meperidine on the newborn infant. Am J Obstet Gynecol 89:1009-1015

5. Brackbill Y, Kane J, Maniello RL, Abramson D 1974 Obstetric meperidine usage and assessment of neonatal status. Anesthesiology 40:116-120

6. Kuhnert BR, Linn PL, Kennard MJ, Kuhnert PM 1985 Effects of low doses of meperidine on neonatal behavior. Anesth Analg 64:335-342

7. Taylor ES, Von Fumetti HH, Essig LL. Goodman SN, Walker LC 1955 The effects of Demerol and trichlorethylene on arterial oxygen saturation in the newborn. Am J Obstet Gynecol 69:348-351

8. Roberts H, Kane KM, Percival N, Snow P 1957 Effect of some analgesic drugs used in childbirth. Lancet $1: 128-132$

9. Koch G, Wendel H 1968 Effect of pethidine on the postnatal adjustment of respiration and acid base balance. Acta Obstet Gynecol Scand 47:27-37

10. Gerhardt T. Bancalari E, Cohen H, Macias-Loza M 1977 Respiratory depres- sion at birth: value of Apgar score and ventilatory measurements in its detection. J Pediatr 90:971-975

11. Berterottiere D, D'Allest AM, Dehan M, Gaultier C 1990 Effects of increase in body temperature on the breathing pattern in premature infants. J Dev Physiol 13:303-308

12. Canet E, Gaultier C, D'Allest AM, Dehan M 1989 Effects of sleep deprivation on respiratory events during sleep in healthy infants. J Appl Physiol 66:11581163

13. Mather LE, Tucker GT 1974 Meperidine and other basic drugs: general method for their determination in plasma. J Pharm Sci 63:306-307

14. Ritschel WA. Adolph S, Denson DD 1990 lon-trapping of meperidine: influence of antacid treatments on serum and gastric fluid concentrations. Methods Find Exp Clin Pharmacol 12:47-51

15. Prechtl HFR 1974 The behavioural states of the newborn infant (a review) Brain Res 76:185-212

16. Curzi-Dascalova L, Peirano P, Morel-Kahn F 1988 Development of sleep states in normal premature and full-term newborns. Dev Psychobiol 21:431-444

17. Dolfin T, Duffy P. Wilkes D. England S, Bryan H 1983 Effects of a face mask and pneumotachograph on breathing in sleeping infants. Am Rev Respir Dis 128:977-979

18. Revow MD, England SJ, Stogryn HAF. Wilkes DL 1987 Comparison of calibration methods for respiratory inductive plethysmography in infants. J Appl Physiol 63:1853-1861

19. Dolfin T, Duffy P, Wilkes DL, Bryan H 1982 Calibration of respiratory induction plethysmography (Respitrace) in infants. Am Rev Respir Dis 126:577-579

20. Migdal M, Dreizzen E. Praud JP, Vial M, Dehan M, Chambille B, Gaultier C 1987 Compliance of the total respiratory system in healthy preterm and fullterm newborns. Pediatr Pulmonol 3:214-218

21. Gerhardt T, Reifenberg L, Duara S. Bancalari E 1989 Comparison of dynamic and static measurements of respiratory mechanics in infants. $J$ Pediatr $114: 120-125$

22. Curzi-Dascalova L, Christova-Gueorguieva E 1983 Respiratory pauses in normal prematurely born infants. A comparison with full-term newborns. Biol Neonate 44:325-332

23. Kryger MH, Yacoub O, Dosman J, Macklem PT, Anthonisem NR 1976 Effect of meperidine on occlusion pressure responses to hypercapnia and hypoxia with and without external inspiratory resistance. Am Rev Respir Dis 114:333-340

24. Douglas NJ, White DP. Weil JV, Pickett CK, Martin RJ, Hudgel DW, Zwillich CW 1982 Hypoxic ventilatory response decreases during sleep in normal men. Am Rev Respir Dis 125:286-289

25. Douglas NJ, White DP, Weil JV, Pickett CK, Zwillich CW 1982 Hypercapnic ventilatory response in sleeping adults. Am Rev Respir Dis 126:758-762

26. Rigatto H, Kalapesi L, Leahy FN, Durand M, McCallum M, Cates D 1982 Ventilatory response to $100 \%$ and $15 \% \mathrm{O}_{2}$ during wakefulness and sleep in preterm infants. Early Hum Dev 7:1-10

27. Praud JP, Egreteau L, Benlabed M, Curzi-Dascalova L, Nedelcoux H, Gaultier C 1991 Abdominal muscle activity during $\mathrm{CO}_{2}$ rebreathing in sleeping neonates. J Appl Physiol 70:1344-1350

28. Hodgkinson $R$, Bhatt $M$, Wang $C N 1978$ Double-blind comparison of the neurobehaviour of neonates following the administration of different doses of meperidine to the mother. Can Anaesth Soc J 25:405-411

29. Szeto HH, Zervoudakis IA, Cederqvist LL, Inturrisi CE 1978 Amniotic fluid transfer of meperidine from maternal plasma in early pregnancy. Obstet Gynecol 52:59-62

30. Seeds AE, Hellegers AE 1968 Acid-base determinations in human amniotic fluid throughout pregnancy. Am J Obstet Gynecol 101:257-260

31. Inturrisi $C E$, Blinick $G 1973$ The quantitation of methadone in human amniotic fluid. Res Commun Chem Pathol Pharmacol 6:353-356

32. Avery GB, Randolph JG, Weaver T 1966 Gastric acidity in the first day of life. Pediatrics 37:1005-1007

33. Trudnowski RJ, Gessner T 1979 Gastric excretion of intravenously administered meperidine in surgical patient. Anesth Analg 58:88-92

34. Stoeckel H, Hengstmann J, Schuttler J 1979 Pharmacokinetics of fentanyl as a possible explanation for recurrence of respiratory depression. $\mathrm{Br} \mathrm{J}$ Anaesth 51:741-745

35. Bolton DP. Hermans J 1974 Ventilation and sleep state in the newborn. J Physiol (Lond) 240:66-77

36. Hathorn MK 1974 The rate and depth of breathing in newborn infants in different sleep states. J Physiol (Lond) 243:101-113

37. Haddad GG, Epstein RA, Epstein AF, Leistner HL, Marino PA, Meilins RB 1979 Maturation of ventilation and ventilatory pattern in normal sleeping infants. J Appl Physiol 46:998-1002 